\title{
Investigation of Certain Serological Reactions in Leprosy.
}

E. SLACK.

'The Muller-Ballung's Reaction.

CHE following techniquc, as described at the serodiagnostic laboratory, the Allgeneine Kvankenhaus,

1 Vienna, for the diagnosis of syphillis, has been applied by me in the course of blood work in a few cases of leprosy. The necessary ingredients are as follows:-

1. Inactivated serum, as in the Khan's Reaction.

2. Carbonated physiological saline.

3. Antigen. 


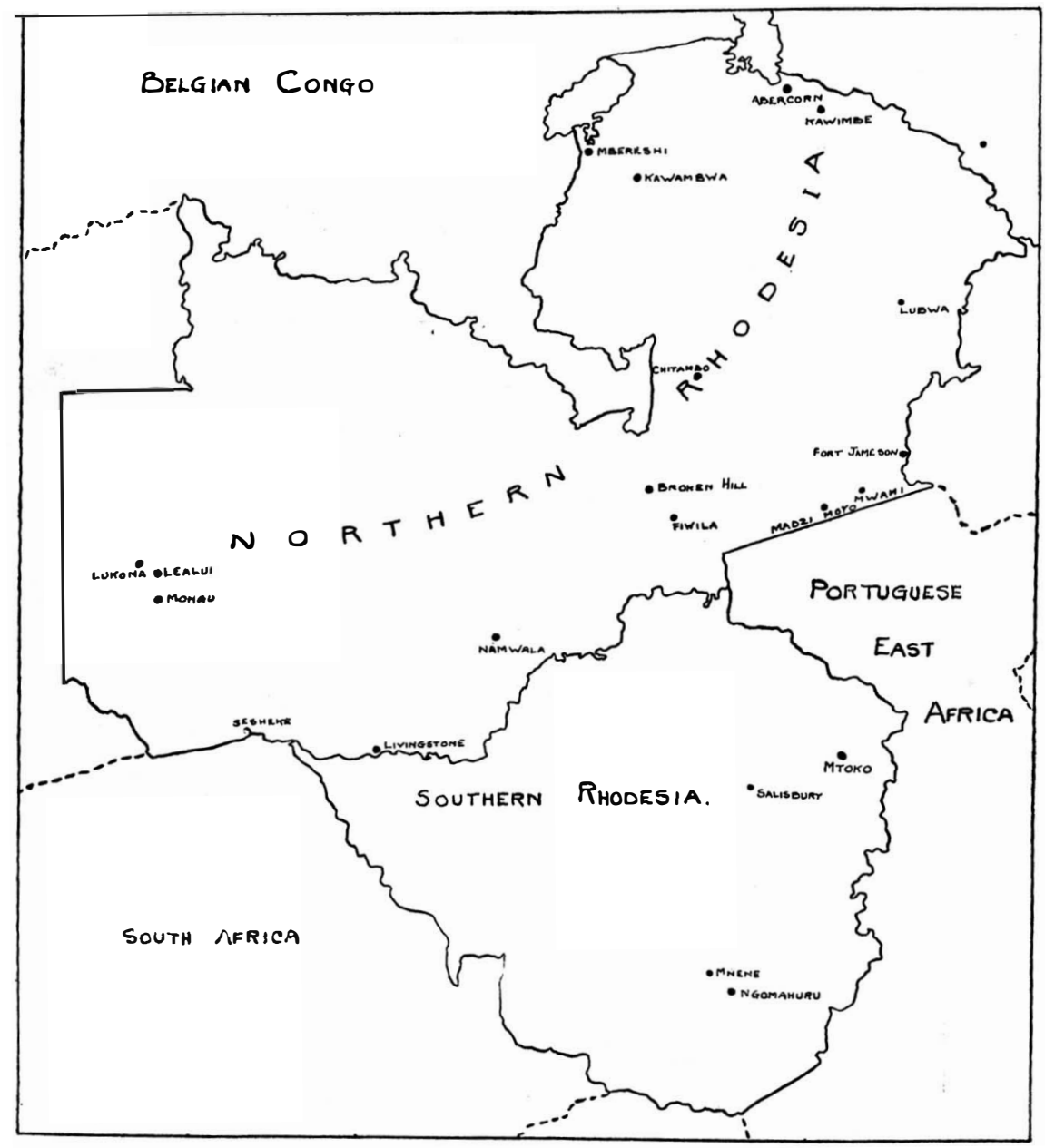

Sketch Map of Northern and Southern Rhodesia, showing Main l'reatment Centres. 


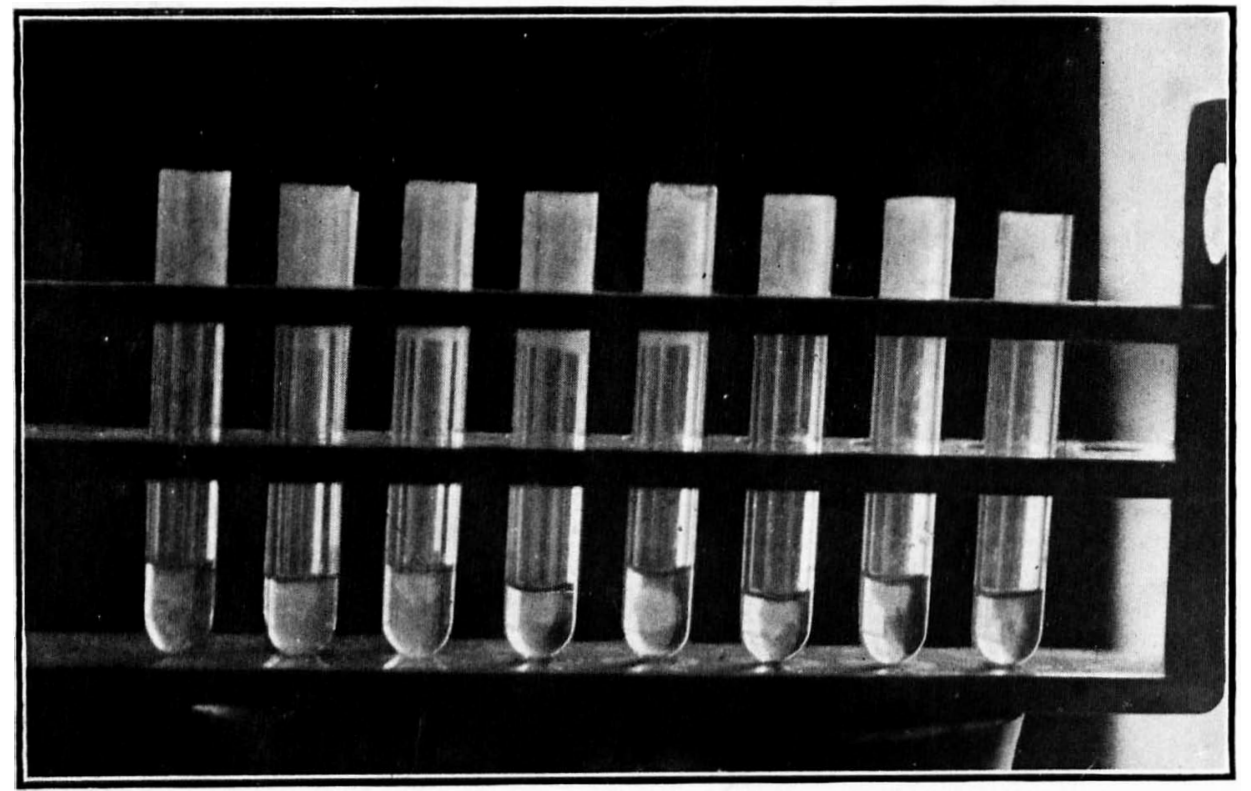

Fici. 1

Balievg's Test on Casfe of Leprosy Selfectei from Various Types $\left(\mathrm{N}_{1}, \mathrm{~N}_{2}, \mathrm{C}_{1}, \mathrm{C}_{2}\right)$-Pusitwes.

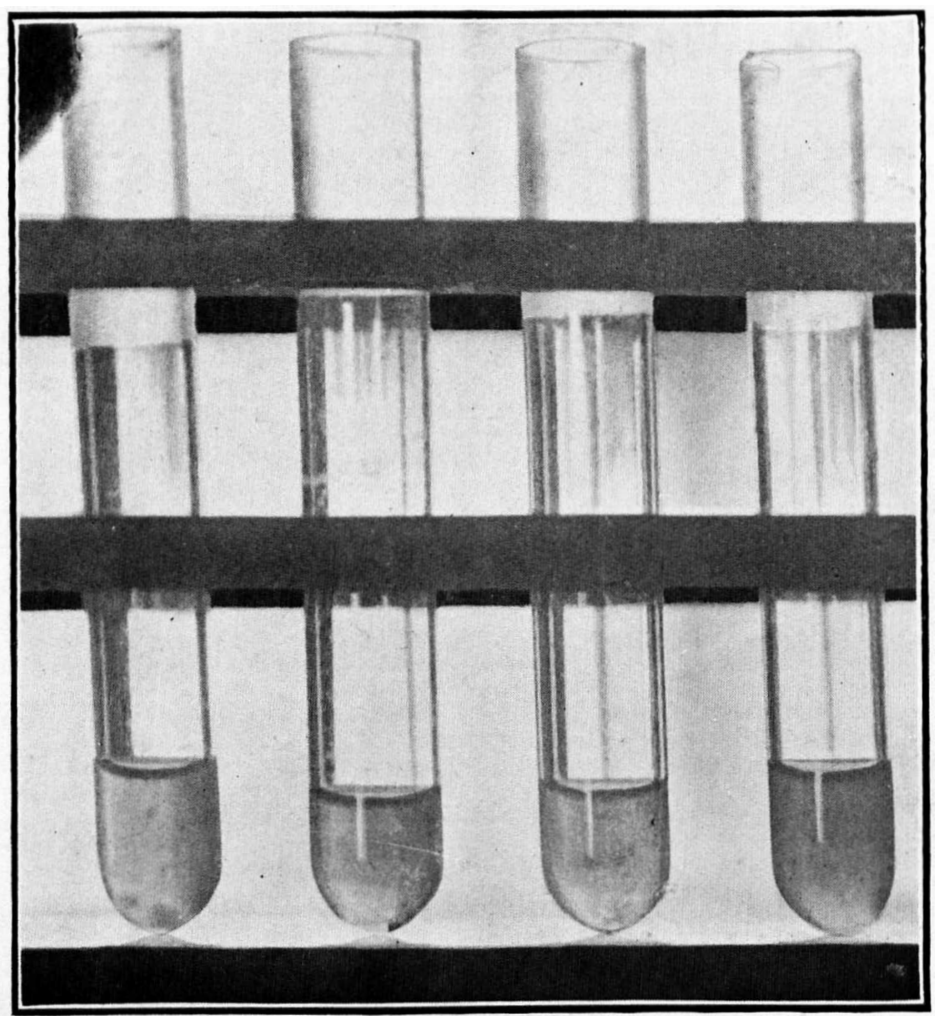

FIG. 2.

Ballung's Test.-Contrast Appearance of 1hese Nigative Controls with Fig. 1.

'These photos were taken after 20 hours' standing, i.e., after completion of test. 
The composition of the physiological saline, which when used must be at the temperature of $17^{\circ} \mathrm{C}$., is prepared thus :-

(a) 97 c.c., 0.9 per cent. saline.

(b) 3 c.c., 0.9 per cent. saline, to which natrium carbonate is added.

Now $(b)$ is made thus :-

To 99 c.c. of 0.9 per cent. saline, 1 gramme natrium carbonate is added. From the resultant (b) give 3 c.c.

In order to prepare your colloidal antigen, the following is the method advised for the Ballung's Reaction :-

Take 2 c.c. of the alchoolic antigen in a test tube. Blow in 3 c.c. of special saline, and point actually on the wall of the tube quickly. Turn it twice over with the thumb. Let it stand ten minutes. Shake it twice. Wait two minutes. Take a dry beaker, and pour contents of tube into this beaker. Pour 25 c.c. of special saline into it (i.e., the natrium saline). The colloidal antigen for this particular reaction is thus prepared.

Now suck up into pipette 5 drops of inactivated serum, and blow into No. " $1 \mathrm{~A}$ " tube. Suck up 7 drops, and blow into " $1 \mathrm{~B}$ " tube. These two tubes can, of course, only be used when there is sufficient serum from the patient's blood. If insufficient, then only one can be supplied. The object of the duplication of tubes is that it is easier to observe if a mistake has been made, and also it emphasises the difference between the strongly and the weakly infected patients. From each tube of serum, blow in $\mathbf{5}$ and $\mathbf{7}$ drops respectively when sufficient serum. Add 0.5 c.c. of colloidal antigen, and at once turn over with thumb against the end of the tube. When all is completed, put them all into water bath $\left(55^{\circ}\right.$ to $\left.56^{\circ}\right)$ for 15 minutes. Then take out, and place in room temperature $\left(20^{\circ}\right.$ to $\left.24^{\circ}\right)$, letting stand for three hours.

\section{Remarks on the Ballung's Reaction.}

In my limited experience of this test it is not till after seventeen hours that one is able to see what may be described as the typical "snowball" reaction. After three hours' standing one may see the contents only clear or semiopaque, or else showing a flocculent appearance. The "snowball " in a typical positive case is suspended half-way between the upper level of the fluid and the bottom, as demonstrated in a photo that I recently forwarded to the Secretary of the Association. The negatives done from the Superintendent and myself show flocculation, but nothing of a definite formation. The other positives were the result of tests carried out on serums from cases, some of whom were. 
early, and some advanced. It is obviously necessary to do work on some hundreds of cases before a definite appreciation of its true value can be formed.

In conclusion, I have to add that it is necessary to purchase the alcoholic antigen for the respective tests from the makers, and up till now I have been using material brought with me from Vienna.

The Meinicke and Trubung's Reaction.

Having arranged in front of you a series of small glass tubes with numbers greased on according to the number of patients you wish to be examined, with clean sterilised pipette draw off 4 drops (=0.2 c.c.) of serum, and blow into your new tube with numbers corresponding. After each has received the drops, blow the adherent drops into empty glass. Suck up saline and blow out in order to clean, care being taken in each case not to disturb the lower portion consisting of blood clot. Repeat the process till all the tubes have received their 4 drops.

\section{Preparation on Colloidal Antigen. Importance of CARRYING THIS OUT IN A HOT CHAMBER.}

Proceed to the hot chamber (or oven), the temperature. of which should be from $40^{\circ}$ to $50^{\circ} \mathrm{C}$., and make your colloidal antigen from the extract of alcoholic antigen, which latter article can be bought. The procedure is as follows :-

Take a 10 c.c. pipette, dry (and coloured for preference for the sake of distinction). Suck up 10 c.c. from a 3 per cent. saline solution and blow out into a clean glass " A." (Proportions taken are 1 c.c. antigen to 10 c.c. 3 per cent. saline.) Again, with a fresh pipette (with another colouring), suck up 1 c.c. antigen from the alcoholic antigen, and blow into glass "B." Quickly pour the "A" (saline) into " B" (alcoholic extract), and pour backwards and forwards. All this is done in the hot chamber (or paraffin stove). The colloidal antigen is thus prepared.

Returning to your table; on which is the rack holding the tubes with the serums to be tested, blow in 1 c.c. of the colloidal antigen into each tube as rapidly as possible, and shake well. Read against the bars of the window or the filaments of an electric globe.

Results can be classed as strongly positive, strongly negative, or weak, according to their degree of opacity. First reading after first hour,- second reading after three hours. After forty-eight hours' standing, the positive clear up, leaving a sediment at the bottom. 
Notes on Reaction.

1. There is no inactivation by means of a hot water bath in this reaction, in contradistinction to the Kahn and Ballungs Reaction, in which the serums are placed in hot water bath.

2. In the case of the Ballung, it is necessary to use ice when working in hot climates or laboratories to reduce the temperature of the saline to $17^{\circ} \mathrm{C}$. On the other hand, heat in winter time, but up to the present time (end of winter) the writer has had to use heat.

Since writing about the Ballung and Meinicke and Trubung tests I have devoted myself almost exclusively to the Ballungs, which, in my opinion, though not easier to do, gives the most decisive results. I have worked on the serums of 33 patients, and have tried to exclude as far as possible any syphilitic taint from that number. Results according to the Manila classification are as follows :-

Results, 1931. To end of September.

N1. All cases (numbering five only) of N1 (early) were feebly positive, the snowball appearing after 17 hours standing, but quite definite.

$\mathrm{N1}, \mathrm{Cl}$. 75 per cent. of this class positive, two cases being strongly so, one weak, and one negative.

N2, C1. 66 per cent. positive, though weakly so.

C1. 30.7 per cent. positive.

C2. 83 per cent. positive. 